\title{
Impact of the Next Gen PET Curriculum on Science Identity
}

\author{
Robynne M. Lock, ${ }^{1}$ Ben Van Dusen, ${ }^{2}$ Steven Maier, ${ }^{3}$ and Liang Zeng ${ }^{4}$ \\ ${ }^{1}$ Department of Physics \& Astronomy, Texas A\&M University-Commerce, Commerce, TX, 75429, USA \\ ${ }^{2}$ Department of Science Education, California State University Chico, Chico, CA, 95929, USA \\ ${ }^{3}$ Department of Natural Science, Northwestern Oklahoma State University, Alva, OK, 73717, USA \\ ${ }^{4}$ Department of Physics \& Astronomy, The University of Texas Rio Grande Valley, Edinburg, TX, 78539, USA
}

The Next Gen Physical Science and Everyday Thinking (PET) curriculum was designed for physical science courses for future elementary teachers. However, this curriculum may also be used in general education conceptual science courses. The materials are aligned with the Next Generation Science Standards and use a guided-inquiry approach. Next Gen PET is currently being implemented at many universities nationwide. We examine the impact of this curriculum on students' science identities at a subset of these universities. The identity framework consists of three dimensions. Recognition is the extent to which a student believes that parents, peers, and professors view them as a science person. Interest describes their enjoyment of science. Finally, performance/competence represents a student's belief in their abilities to understand science and complete science related tasks. The shift in science identities was measured with items adapted from a previously developed physics identity instrument. We found positive shifts in the science identities of students enrolled in face-to-face courses targeted at pre-service teachers using the Next Gen PET curriculum, but a slight negative shift in the science identity of students enrolled in an online course targeted at non-science majors which did not use the Next Gen PET curriculum.

2019 PERC Proceedings edited by Cao, Wolf, and Bennett; Peer-reviewed, doi.org/10.1119/perc.2019.pr.Lock Published by the American Association of Physics Teachers under a Creative Commons Attribution 4.0 license. Further distribution must maintain attribution to the article's authors, cover page, and DOI 


\section{INTRODUCTION}

In order to improve the quality of K-12 science education, teacher preparation programs need to prepare teachers who are confident in teaching science using inquiry-based methods at all levels. While this is difficult at the secondary level, the challenge is more extreme at the elementary level. Pre-service elementary teachers frequently lack confidence in teaching science due to their low levels of scientific knowledge and preexisting negative perceptions of the nature of teaching science [1]. To better prepare teachers, teacher preparation programs should be examined for how they impact future teachers' science identities. Science teacher identity has been found to relate to how likely teachers are to implement reformed teaching practices such as inquiry-based instruction and discussing the nature of science [2].

Most work on science teacher identity has focused on future secondary teachers. However, the development of the science teacher identity of preservice elementary teachers has also been explored [1]. Science teacher identity has been characterized by a range of components including confidence, recognition by others, subject matter knowledge, emotions, interest, view of self as a science teacher, beliefs about science teaching, and membership in a community of colleagues $[2,3]$. Science identity is an important component of science teacher identity. While science identity has been defined in a variety of ways, in this work, we adapt the physics identity framework developed by Hazari et al. [4] for science more generally. This framework consists of three components. Recognition refers to the perception that others see an individual as a "science person". Interest represents the extent to which the individual wants to learn more about science or enjoys science. Finally, performance/competence describes the individual's beliefs about their abilities to demonstrate their scientific skills and their beliefs about their own understanding of science.

While building the science identity of preservice teachers can be expected to improve the quality of their teaching, increasing science identity can benefit other students as well through increasing their engagement with science [2]. Students more engaged with science may learn more and have a greater appreciation of science. Finally, increasing disciplinebased identity has previously been found to benefit efforts to recruit students into STEM majors. Physics identity predicts physics career intentions, while together physics and math identity predict engineering career intentions [4, 5].

Factors that may impact science teacher identity have largely been examined through qualitative studies. These factors include teacher preparation program components such as methods courses and field experiences as well as informal science experiences and personal histories [2]. However, prior work has not delineated between science identity and science teacher identity. In this work, we examine the impact of the Next Gen PET (NGP) curriculum on science identity.

NGP is a research-based curriculum intended primarily for university courses in physics or physical science for prospec- tive elementary teachers $[6,7]$. NGP extends the work completed on prior PET curriculum $[8,9]$ to modernize the technological components, integrate the three dimensions of the Next Generation Science Standards [10], and create modules that can be used in either lab or lecture settings. As NGP is designed to be used with future elementary teachers, many of whom have not had positive prior science experiences, one of its goals is to promote students thinking like and identifying as scientists. To promote shifts in students attitudes toward science, the NGP curriculum uses a proven, guidedinquiry approach that engages future teachers in many of the practices of science while developing a deep understanding of core ideas of physics or physical science.

\section{RESEARCH QUESTIONS}

By examining science identity survey data, we investigate the research questions: (1) What is the impact of physical science courses taught using NGP on students' science identities? (2) How does the impact on science identity vary across different physics or physical science course implementations?

\section{METHODS}

\section{A. Data collection}

Science identity surveys were administered to physical science classes at the beginning and end of the Spring 2019 semester. The science identity instrument was adapted from a pre-existing physics identity survey and physic/math identity items on the SaGE survey [11, 12]. Physics specific items were removed or adapted for general science. The survey included items on science recognition, interest, and performance/competence along with items on gender, race, and ethnicity.

Instructors at three different universities administered the surveys. They were recruited through the NGP Faculty Online Learning Community (FOLC). Table I summarizes the characteristics of the courses from which data was collected. Two of the courses were at University A with one of these classes being a general physics course for non-science majors and one of them being a physics course targeted at pre-service elementary teachers. The latter course used the NGP curriculum, while the former did not. The courses at Universities B and $\mathrm{C}$ were both targeted at pre-service elementary teachers and used the NGP curriculum, though at University B, liberal arts majors also enrolled in the course. The table shows the gender, race, and ethnicity of the students.

Beyond the differences in the classes, the University contexts differ. Universities A and B are both public research universities with a student population nearing 30,000. However, these universities differ in that University A is primarily a residential campus and not a Hispanic Serving Institution (HSI), while University B is primarily a commuter campus and is 
TABLE I. Course characteristics. Percentages may not sum to $100 \%$ because categories are not mutually exclusive.

\begin{tabular}{|c|c|c|c|c|c|c|c|}
\hline Course & University & Student number & Curriculum & Delivery method & Student type & Gender & Race/Ethnicity \\
\hline 1 & A & 55 & Non-NGP & Online & Non-science majors & $\begin{array}{l}78 \% \text { female, } 22 \% \text { male, } \\
2 \% \text { genderqueer }\end{array}$ & $\begin{array}{l}\text { 4\% Black, 5\% Hispanic/Latino, } 2 \% \text { Asian or Pa- } \\
\text { cific Islander, } 95 \% \text { White }\end{array}$ \\
\hline 2 & A & 42 & NGP & Face-to-Face & $\begin{array}{l}\text { Pre-service elementary } \\
\text { teachers }\end{array}$ & $100 \%$ female & $\begin{array}{l}2 \% \text { Black, } 2 \% \text { Hispanic/Latino, } 12 \% \text { American In- } \\
\text { dian or Alaskan Native, } 98 \% \text { White }\end{array}$ \\
\hline 3 & B & 27 & NGP & Face-to-Face & $\begin{array}{l}\text { Pre-service elementary } \\
\text { teachers, Liberal arts } \\
\text { majors }\end{array}$ & $74 \%$ female, $26 \%$ male & $89 \%$ Hispanic/Latino, $78 \%$ White \\
\hline 4 & $\mathrm{C}$ & 45 & NGP & Face-to-Face & $\begin{array}{l}\text { Pre-service elementary } \\
\text { teachers }\end{array}$ & $91 \%$ female, $9 \%$ male & $\begin{array}{l}2 \% \text { Black, } 29 \% \text { Hispanic/Latino, } 4 \% \text { American In- } \\
\text { dian or Alaskan Native, } 9 \% \text { Asian or Pacific Is- } \\
\text { lander, } 82 \% \text { White }\end{array}$ \\
\hline
\end{tabular}

an HSI. University $\mathrm{C}$ is a commuter campus and HSI, similar to University B, but is not classified as a high research activity university by Carnegie. All three universities are public. Thus students are situated in wide range of contexts which may impact their classroom experiences.

Instructors matched data and removed identifiers, so the percentage of missing data and the overall response rate are unknown.

\section{B. Data analysis}

Prior to analyzing the data for trends in the three factors that the science identity survey was designed to measure, we examined the data to ensure that the factors were emerging in the data. To do this, we performed a maximum-likelihood factor analysis using the factanal function in R. The analysis identified the three sub-construct factors that were a priori expected to emerge (science recognition, interest, and performance/competence) and each question loaded into the factor it was expected to load into with the exception of one item that was subsequently removed from the analysis.

Each student response was scored on a scale of 1-5 with a 1 representing the lowest science identity value and 5 highest science identity. Treating scale response data as interval, as we did, rather than as ordinal is commonly critiqued. Researchers have found, however, that when examining multiple rating scale items in aggregate the data can be treated as continuous without introducing bias [13-15]. Further, responses to individual items with at least 5 response options can generally be treated as continuous values [16-18].

An average overall science identity score was calculated for each student as well as a score for each sub-construct. Descriptive statistics, including pretest, posttest, and gains (posttest - pretest), were then calculated for each course broken out by sub-construct. To contextualize the size of the average gains in science identity scores in each course, Cohen's $d$ values were calculated [19].

Our analysis and reporting of findings do not include comparison of differences in groups' mean scores using p-values. This was done deliberately to follow the advice of the American Statistical Association [20-22], which recommends replacing the traditional use of $\mathrm{p}$-values in research with mea-
TABLE II. Overall science identity score descriptive statistics.

\begin{tabular}{cccccccc}
\hline \hline \multirow{2}{*}{ Course } & \multicolumn{3}{c}{ Pretest } & \multicolumn{2}{c}{ Posttest } & \multicolumn{3}{c}{ Gain } \\
& Mean & SE & Mean & SE & Mean & SE & $d$ \\
\hline 1 & 1.99 & 0.10 & 1.77 & 0.11 & -0.22 & 0.09 & -0.25 \\
2 & 2.10 & 0.11 & 2.39 & 0.12 & 0.29 & 0.10 & 0.40 \\
3 & 2.21 & 0.17 & 2.74 & 0.15 & 0.53 & 0.11 & 0.64 \\
4 & 2.32 & 0.11 & 2.85 & 0.09 & 0.53 & 0.10 & 0.80 \\
\hline \hline
\end{tabular}

sures that promote critical thinking about the meaning of uncertainty. In lieu of reporting p-values, we represent the uncertainty in mean scores using standard errors.

\section{FINDINGS}

The online course (course 1) had a lower pretest average science identity score than the three courses that used the NGP curriculum (courses 2, 3, and 4) (Table II). The gap in scores between the online and NGP courses was wider in the posttest scores. The online course had a small negative effect $(d=-0.25)$ on overall science identity scores, while the NGP courses had positive effect sizes that ranged from small to large $(0.4 \leq d \leq 0.8)$.

The gains in overall science identity and its three subconstructs are shown in Figure 1(a-d). While the average gain in overall science identity, shown in Figure 1a, are equal for courses 3 and 4, the effect size for course 4 was larger (Table II) due to it having a smaller standard deviation. The science identity recognition sub-construct, shown in Figure 1b, had the largest gains across all of the sub-constructs (-.07 to 0.66$)$. The science identity interest sub-construct, shown in Figure $1 \mathrm{c}$, had the smallest range of gains (-.06 to 0.53$)$. The science identity performance/competence sub-construct, shown in Figure 1d had the largest gap in scores between the online and NGP courses.

\section{DISCUSSION AND CONCLUSION}

In all courses using the NGP curriculum, science identity increased in each of the three dimensions (recognition, inter- 


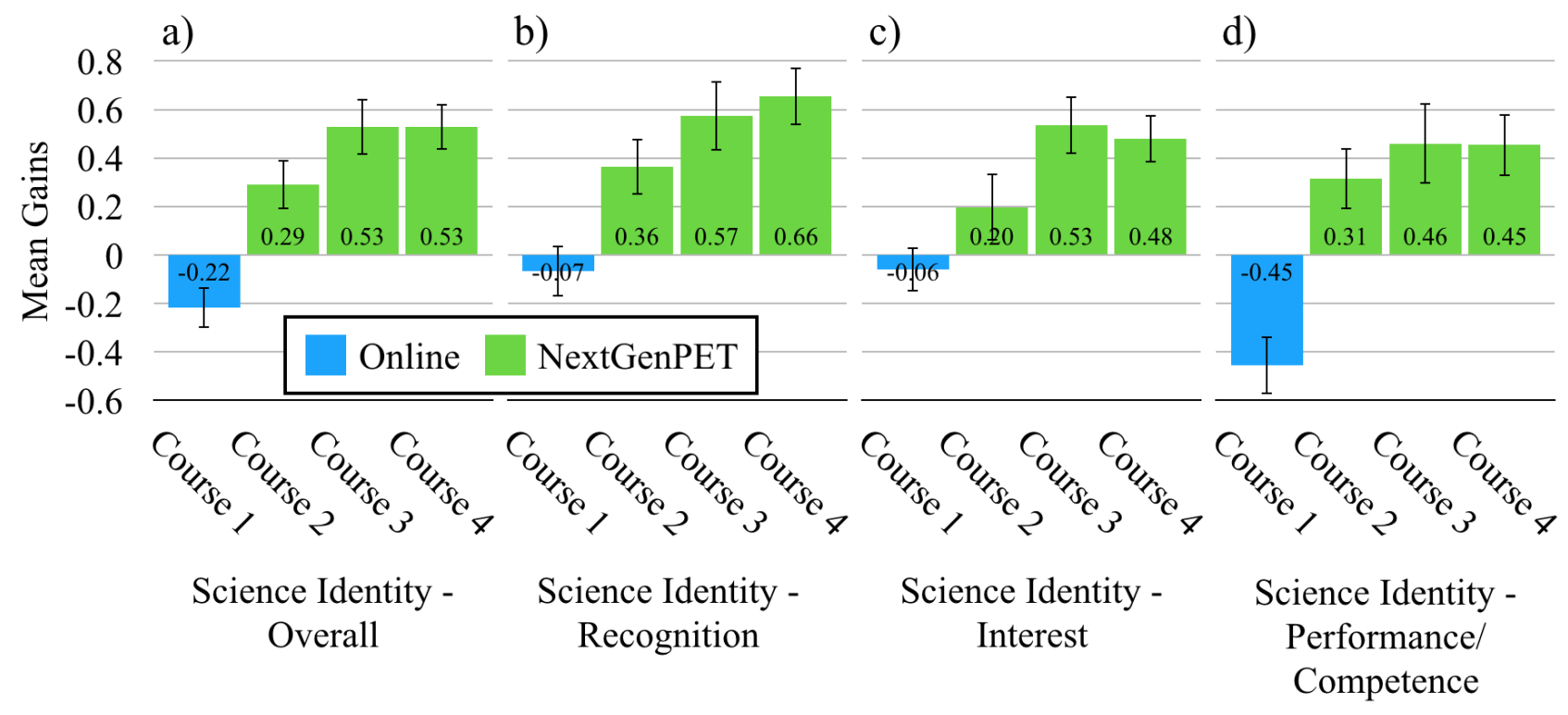

FIG. 1. Mean gains in overall science identity and its three sub-constructs dissagregated by course. Error bars represent $+/-1$ standard error.

est, and performance/competence). However, in the course which did not use the NGP curriculum, science identity slightly decreased, with the bulk of the decrease due to declines in performance/competence. The difference in impact of the courses on science identity may be due to a number of factors. The courses using the NGP curriculum were all faceto-face and the majority of students were pre-service teachers, while the course that did not implement the NGP curriculum was online and the majority of students were general nonscience majors. Thus, it is possible that the difference is due to the delivery method of the course or the students' majors. Nonetheless, the positive shift in identity in the courses using the NGP curriculum is encouraging given the close association of science identity and science teacher identity. Because science teacher identity is linked to teachers implementing reformed teaching methods, such an improvement is likely to result in more teachers graduating from these programs that are likely to use teaching practices such as inquiry-based instruction that incorporates discussion of the nature of science [2].

The shifts in identity in each course vary with identity component. The largest shifts in identity occurred in the recognition dimension. The gains in interest and performance/competence were generally smaller. In course 2 , the smallest shift was in interest, while in courses 3 and 4, the smallest shifts were in performance/competence. In prior work on physics identity, recognition has been found to be the most important dimension for physics career intentions [12]. If the role of science identity in teacher practice is similar to the role of physics identity in physics career intentions, then the larger gains in science recognition in courses using the NGP curriculum are of key importance. Conversely, performance/competence has been found to be the least impor- tant dimension of physics identity when considering physics career intentions [12]. Hence, smaller gains in science performance/competence compared to recognition indicate that the NGP curriculum has the largest impact on the most important aspects of identity, although the components are all closely related.

The goals of NGP align with science identity development as it aims to help students to think like scientists. Students engage in scientific practices which may be expected to improve their science recognition. Connections are made to everyday applications which may lead to increased science interest. Finally, deep understanding of physical science concepts is developed as the class together constructs scientific knowledge which should result in increases in science performance/competence.

Recognition by others as a teacher with expertise in science has been described as essential to science teacher identity [2], thus underscoring the importance of a curriculum for preservice teachers that builds recognition as a "science person". Other work on new teachers' identity development highlighted the difficulties teachers encounter when expected to be an expert in a subject they dislike [2]. Therefore, the positive shifts in interest hold significance for improving the practice of new teachers. Finally, confidence in science knowledge and teaching science are associated with overcoming difficulties with implementing inquiry-based teaching practices and incorporating other new content into the curriculum [2], thus indicating the importance of curricula that increase future teachers' science performance/competence. The positive impact of courses using the NGP curriculum on the three science identity dimensions hence can be expected to result in improved teaching quality.

More information about the specific implementation of the 
NGP curriculum in the three different courses is needed in order to understand the origin of the impacts on science identity and why the impacts on science identity vary between courses. NGP is a flexible curriculum consisting of 10 different units and the materials are available in formats for both lecture and studio environments. Instructors select which units to include in their course and which format is most appropriate for their context. Hence, each of these three courses used a different combination of units and in different formats. A sample including more courses and full information about these factors in those classes would provide further insight into the effect of these elements. Finally, instructor's individual implementations will vary.

An additional reason for the variation between the identity shifts in the three face-to-face NGP classes may be that they were taught at three different universities by three different instructors. Courses 3 and 4 appear to have more similar identity shifts to each other than they do to Course 2, so examination of the characteristics that Universities B and $\mathrm{C}$ have in common and are different for University A may yield some insight. Universities B and C are both HSIs, while University A is not. Furthermore, Universities B and C are largely commuter campuses, while University A is primarily a residential campus. The context of these universities likely affects the experiences of students in their NGP courses. The factor that Universities A and B have in common is that they are both large, research universities, so this difference is likely to be less important. A larger sample including courses at a larger variety of universities would allow for better analysis of the importance of these factors.

Impacts of physics and physical science courses on the science identity of non-science majors not intending to become teachers should also be considered. The course targeted at this audience did not use the NGP curriculum, and the students enrolled in this course experienced negative shifts in identity. This negative impact on identity constrasts with the positive impact found for the three courses using the NGP curriculum. However, this difference in effect on identity cannot entirely be attributed to the choice of curriculum. Nonscience majors with no intent of becoming teachers may respond to physics and physical science courses differently than future teachers. Furthermore, the course 1 students had lower pretest scores than those in the other three courses. Another important factor is that this class was taught online. While the university and instructor can be expected to affect identity shifts, courses 1 and 2 were taught at the same university by the same instructor, so this is unlikely to be the source of the difference. Importantly, the shift in iden- tity in course 1 is largely neutral except for the effect on performance/competence. While the negative shift in science identity is unfortunate, the effect of this shift on students' engagement with and appreciation of science is likely to be minimized because of the lesser importance of performance/competence found in previous work on physics identity [12].

\section{LIMITATIONS AND FUTURE RESEARCH}

This study was an initial investigation of science identity shifts of students enrolled in postsecondary physics and physical science courses. The short time line and exploratory nature of the work limited the rigour of the statistical analysis. For example, instructors prepared the data by matching pretest and posttest scores but did not report the percentage or features of the missing data. While we believe that the participation rates in these courses were relatively high, it is unlikely that the data was missing completely at random and likely biased our findings [23]. To limit the bias introduced by missing data, we recommend that future research perform multiple imputation prior to statistical analysis [24]. The size of the dataset led us to analyze the data relying primarily on descriptive statistics. As the dataset grows, we recommend researchers perform a more rigorous statistical analysis that includes hierarchical linear models that leverages the nested structure of the dataset and accounts for both course and student level variables [25].

Courses using the NGP curriculum were shown to increase the science identities of enrolled students, while an online course was found to overall negatively impact science identity primarily due to a decline in performance/competence. While these results indicate that the NGP curriculum may form an important component of teacher preparation programs through improving students' science and science teacher identities and hence improving the quality of new teachers' instruction, a larger sample with courses in a larger variety of contexts is needed to separate course and student level factors that may impact the effect of physics and physical science courses on science identity. Finally, while science identity and science teacher identity are related, their relationship needs to be made more concrete and defined. Future work should investigate this relationship as well as the effect of science identity on non-science majors more generally.

\section{ACKNOWLEDGMENTS}

This work is funded in part by NSF-IUSE Grant No. DUE1525338 and NSF Grant No. DUE-1626496.
[1] J. L. Chen and F. M. Mensah, Teaching contexts that influence elementary preservice teachers' teacher and science teacher identity development, Journal of Science Teacher Education
29, 420 (2018).

[2] L. Avraamidou, Studying science teacher identity: current insights and future research directions, Studies in Science Edu- 
cation 50, 145 (2014).

[3] M. Nieswandt, S. E. Barrett, and E. H. McEneaney, Predictors of science subject discipline identities: A statistical analysis, Canadian Journal of Science, Mathematics and Technology Education 13, 90 (2013).

[4] Z. Hazari, G. Sonnert, P. M. Sadler, and M.-C. Shanahan, Connecting high school physics experiences, outcome expectations, physics identity, and physics career choice: A gender study, Journal of Research in Science Teaching 47, 978 (2010).

[5] A. Godwin, G. Potvin, Z. Hazari, and R. Lock, Identity, critical agency, and engineering: An affective model for predicting engineering as a career choice, Journal of Engineering Education 105, 312 (2016).

[6] F. Goldberg and E. Price, Working with next gen pet and joining a faculty online learning community, Bulletin of the American Physical Society 62 (2017).

[7] E. Price, Next gen pet: An effective, ngss-aligned curriculum for future elementary teachers, Bulletin of the American Physical Society (2019).

[8] V. K. Otero and K. E. Gray, Attitudinal gains across multiple universities using the physics and everyday thinking curriculum, Physical Review Special Topics-Physics Education Research 4, 020104 (2008).

[9] F. Goldberg, V. Otero, and S. Robinson, Design principles for effective physics instruction: A case from physics and everyday thinking, American journal of physics 78, 1265 (2010).

[10] N. R. Council et al., Guide to implementing the next generation science standards (National Academies Press, 2015).

[11] G. Potvin, K. Paige, and C. Beattie, Building a valid and reliable assessment of physics identity, in 2012 Proceedings of the National Association for Research in Science Teaching.

[12] R. M. Lock, Z. Hazari, and G. Potvin, Physics career intentions: The effect of physics identity, math identity, and gender, AIP Conference Proceedings 1513, 262 (2013).

[13] S. E. Harpe, How to analyze likert and other rating scale data, Currents in Pharmacy Teaching and Learning 7, 836 (2015).

[14] A. R. Baggaley and A. L. Hull, The effect of nonlinear transfor- mations on a likert scale, Evaluation \& the health professions 6, 483 (1983).

[15] S. Labovitz, The assignment of numbers to rank order categories, American sociological review , 515 (1970).

[16] J. Van Dusen, Ben Nissen, Criteria for collapsing rating scale responses: A case study of the class, 2019 PERC proceedings (in press).

[17] T.-C. Hsu and L. S. Feldt, The effect of limitations on the number of criterion score values on the significance level of the f-test, American Educational Research Journal 6, 515 (1969).

[18] B. M. Byrne, Structural equation modeling with AMOS: Basic concepts, applications, and programming (Routledge, 2016).

[19] J. M. Nissen, R. M. Talbot, A. N. Thompson, and B. Van Dusen, Comparison of normalized gain and cohen's d for analyzing gains on concept inventories, Physical Review Physics Education Research 14, 010115 (2018).

[20] V. Amrhein, S. Greenland, and B. McShane, Scientists rise up against statistical significance (2019).

[21] R. L. Wasserstein, N. A. Lazar, et al., The asa's statement on p-values: context, process, and purpose, The American Statistician 70, 129 (2016).

[22] R. L. Wasserstein, A. L. Schirm, and N. A. Lazar, Moving to a world beyond "p < 0.05", The American Statistician 73, 1 (2019), https://doi.org/10.1080/00031305.2019.1583913.

[23] J. R. Cheema, A review of missing data handling methods in education research, Review of Educational Research 84, 487 (2014).

[24] J. Nissen, R. Donatello, and B. Van Dusen, Missing data and bias in physics education research: A case for using multiple imputation, Physical Review Physics Education Research 15, 020106 (2019).

[25] B. Van Dusen and J. Nissen, Modernizing use of regression models in physics education research: A review of hierarchical linear modeling, Physical Review Physics Education Research 15, 020108 (2019). 